\title{
Training doctors - too long in the cellar?
}

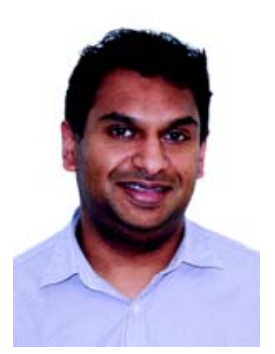

Astika Kappagoda MB BS, MPhil, PhD, Deputy Editor

akappagoda@ mja.com.au

doi: 10.5694/mjal2.c0507

doi: $10.5694 / \mathrm{m}$ al2.c0507$$
\begin{aligned}
& \text { society has a right to expect a working career of sufficient } \\
& \text { length as a return on this investment. }
\end{aligned}
$$

Medical students and doctors-in-training are the most affected by this issue, particularly with the recent growth in the number of medical schools, many of which require graduate entry. After at least 6-7 years of education, they are acutely aware of the long hours and years spent in work, training, research and study that jostle with personal obligations around relationships and family. Increasing numbers of new doctors compete for limited training places that are constrained by university, college and health system resources. Many doctors, such as those described by McNamara, recall an unrelentingly tough grind over many years, including often dispiriting work as unaccredited "service registrars". The temptation to move to the private system and financially make up for lost time is too great for some, with major implications for the public system.

Other countries are also grappling with these issues. It has been estimated that medical training time in the United States could be cut by $30 \%$ without diminishing skills or knowledge (JAMA 2012; 307: 1143-1144). But this requires radical rethinking: less generalist training and greater emphasis on providing volume of experience for new clinicians, to create specialists working in a clinical care team. Research training would be reserved for the academically minded. In the Australian context, graduate programs could be trimmed by making the biomedical sciences compulsory prerequisites for admission and allowing specialist streaming within the primary medical degree, to shorten postgraduate training times.

What of the older doctor at the other end of the career trajectory, whose prized experience inevitably becomes overshadowed by cognitive, motor and sensory difficulties? In this issue, Skowronski and Peisah (page 505) argue that ageing intensivists should not mandatorily retire, but instead refocus - on mentoring, teaching and administration, with working hours and responsibilities suited to their abilities.

Waxman (page 498) makes similar arguments for the older surgeon, citing the Royal Australasian College of Surgeons' activities in this area, and raises the possibility of regular competency assessment. Could age-related decline in manual proficiency be one of the reasons that surgeons older than 50 (seemingly at the top of their game) are the most likely to be sued (Avant Surgeon 2011; (7): 4-5)? Perhaps advances in robotic surgery, discussed by Cartmill and Butt (page 497), will provide new opportunities for surgeons with waning dexterity.

There is plenty to consider here and not much time to do so. Increasing longevity and increasing numbers of medical school graduates will put pressure on both ends of the medical career, potentially resulting in a generation of unhappy and embittered younger doctors, and misvalued and inappropriately purposed practitioners of advancing years.

If we are to have a well trained, well adjusted workforce of doctors of all ages, we need to consider shortening and revitalising medical training, and expanding opportunities for older doctors to remain productive. It has always been accepted that making a good doctor, like good red wine, requires the best ingredients, skill and time. But even the best wine will pass its peak if left too long.

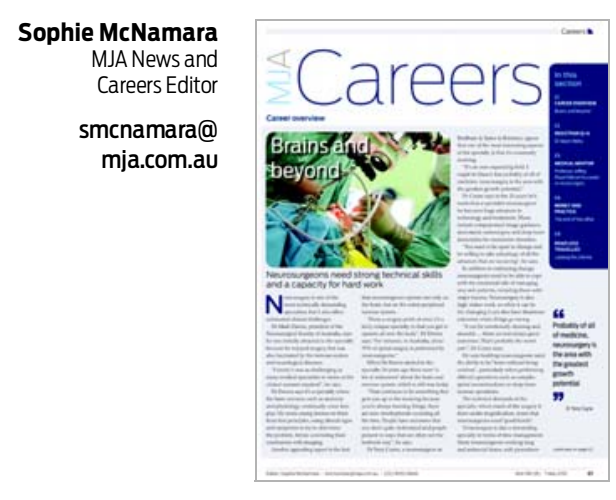

Careers follows $p 536$

\section{Brains on the mind}

Neurosurgery is considered to be one of the most challenging of all careers, as captured by the cliché, "it's not brain surgery". While the neurosurgeons who spoke to MJA Careers for this issue's Career Overview story did emphasise the technical demands of their specialty, they also said the clinical and cognitive challenges of neurosurgery were part of its appeal (page C1). Medical Mentor focuses on neurosurgeon Professor Jeffrey Rosenfeld, who has had an incredible 30-year career encompassing clinical, research and military work, despite being told as a junior doctor that he was not suited to the specialty and should consider something else (page C5)! An equally interesting story is that of a Perth-based cardiologist featured in this issue's Road Less Travelled section. Before arriving in Western Australia in the 1970s, Dr Krishna Somers twice had to flee oppressive political regimes - first from apartheid South Africa and then from Uganda under Idi Amin (page C8). Finally, for doctors wishing to make changes in their working arrangements, Money + Practice provides some practical advice on what to do when a professional partnership ends (page C6). 